\title{
Hepatitis A in Nelson Mandela Bay and Sarah Baartman districts, Eastern Cape, South Africa
}

\author{
Howard Newman $^{a, b *}$, Donald Tshabalalac, Guillermo A. Pulido Estrada ${ }^{d}$ and Romuald Kom Nguetchueng ${ }^{e}$ \\ ${ }^{a}$ Department of Virology, National Health Laboratory Service, Port Elizabeth, South Africa \\ ${ }^{b}$ Department of Pathology, Division of Medical Virology, Stellenbosch University, Cape Town, South Africa \\ 'Department of Paediatrics, Nelson Mandela Central Hospital and Walter Sisulu University, Mthatha, South Africa \\ ${ }^{d}$ Department of Public Health, Walter Sisulu University, Mthatha, South Africa \\ e Outbreak Response Team, Nelson Mandela Bay, Eastern Cape Department of Health, Port Elizabeth, South Africa \\ *Corresponding author, email: howard.newman@nhls.ac.za
}

Check for updates

Background: Hepatitis A is the most common cause of acute viral hepatitis, not only in South Africa, but in many other countries. In South Africa, there is a lack of data regarding the true incidence of hepatitis A, and even fewer data regarding hepatitis A cases requiring hospitalisation. In the Eastern Cape province of South Africa in particular, there is a paucity of published data that could be used to guide public health officials. An analysis of all the laboratory-confirmed cases in the area over a period of time may help to better describe the extent of the problem.

Methods: This was a retrospective study analysing the laboratory-confirmed cases of hepatitis A in the Nelson Mandela Bay and Sarah Baartman districts of the Eastern Cape province in South Africa for the three-year period from 2015 to 2017.

Results: A total of 194 laboratory-confirmed cases of hepatitis A were identified for the three-year period from 2015 to 2017.0 Of these, $138(71 \%)$ cases were children 16 years old or younger, with adults accounting for 56 cases (29\%). There was no overall seasonality associated with laboratory-confirmed cases of hepatitis $A$.

Conclusions: Hepatitis A is a serious problem in the Eastern Cape region. More studies are needed to determine the exact cause of the continuing epidemic.

Keywords: acute hepatitis A, Eastern Cape, hospitalisation rates

\section{Introduction}

Hepatitis $A$ is the most common cause of acute viral hepatitis, not only in South Africa, but in many other countries. ${ }^{1,2}$ Endemicity is low in industrialised countries, and high in resource-poor countries, ${ }^{2}$ with the latter often having complicated epidemiological patterns with variation in incidence across different socioeconomic groups and provinces, ${ }^{1}$ which are closely related to hygiene and sanitary conditions. ${ }^{3}$

The virus is transmitted through the faecal-oral route, mostly through person-to-person spread. In addition, contaminated water or food may serve as a common source vehicle for transmission. ${ }^{1,4}$ Rare forms of transmission include through blood contact and anal-oral sexual contact. ${ }^{4}$

In South Africa, where standards of sanitation and hygiene are low in poor communities, infection commonly occurs in childhood, usually resulting in asymptomatic infection, and confers lifelong immunity to the individual. ${ }^{5}$ In more affluent communities, where sanitation and hygiene are good, infection occurs at an older age, and usually produces more severe disease. ${ }^{4,5}$

The incubation period is $15-50$ days. Individuals are most infectious from two weeks before the onset of jaundice and will remain infectious for approximately two weeks after the onset of jaundice, although prolonged shedding has been documented. ${ }^{1,6}$

Hepatitis A infection is usually a self-limiting disease and in children is mostly asymptomatic. Conversely, older children and adults have a greater chance of presenting with symptoms, sometimes requiring hospitalisation. Clinical presentations include asymptomatic infection, symptomatic hepatitis with or without jaundice, fulminant hepatitis, cholestatic hepatitis or relapsing hepatitis. ${ }^{1,4}$ Most patients who develop jaundice experience a prodromal illness characterised by non-specific symptoms including diarrhoea, abdominal pain, nausea and vomiting. Raised hepatic transaminases are a consistent feature in hepatitis $A$ infection, while mortality rates are generally low (approximately 1\%). ${ }^{1,4}$

Diagnosis of acute or recent hepatitis A infection is achieved by testing for IgM antibodies to the virus.

In South Africa, there is a lack of data regarding the true incidence of hepatitis $A^{1}$ and even fewer data regarding hepatitis A cases requiring hospitalisation. In the Eastern Cape province of South Africa in particular, there is a paucity of published data that could be used to guide public health officials in finding solutions to decrease the disease burden.

A seroprevalence study from South Africa in 1999 showed that $48.3 \%$ of children from lower socio-economic groups at 3-5 years of age were seropositive for anti-hepatitis A IgG antibodies. This figure increases to $86.6 \%$ by $11-13$ years of age. ${ }^{7}$ It is therefore expected that most cases of acute hepatitis $A$ would be children under five years of age.

Since most cases are asymptomatic and compliance with passive notification is poor, an underestimation of hepatitis $A$ cases is expected. ${ }^{1}$ For the same reasons, defining the true 
incidence of hepatitis A cases in the Nelson Mandela Bay and Sarah Baartman districts would be difficult. However, analysis of all the laboratory-confirmed cases in the area over a period of time may help to better describe the extent of the problem.

Due to notifications of new cases of hepatitis A to the Outbreak Response Team of the Nelson Mandela Bay Municipality, we were alerted to the possibility of our region having a high incidence of hepatitis $A$. Whilst not knowing the true incidence of hepatitis $A$ in this region of South Africa, we attempted to define the extent of the problem locally, including hospitalisation rates. Hence this study allowed us to map the occurrence of laboratory-confirmed hepatitis $A$ infections within the various sub districts within the Nelson Mandela Bay and Sarah Baartman districts, which may in future studies point to common sources of infection that can then be targeted by public health officials.

\section{Materials and methods}

We completed a retrospective study of the laboratory-confirmed cases of acute hepatitis A for the three-year period from 2015 to 2017.

The study population comprised all patients who tested positive for hepatitis A IgM at the virology laboratory of the National Health Laboratory Service in Port Elizabeth (NHLS), from January 2015 to December 2017. This laboratory employs the Abbott Architect HAVAb-lgM assay (Abbott Laboratories, Chicago, IL, USA), and serves the entire Nelson Mandela Bay and Sarah Baartman districts, as well as sections of the Chris Hani district. The Nelson Mandela Bay district has a population of approximately 1.2 million, while the Sarah Baartman district has approximately 470000 inhabitants. ${ }^{8}$ The NHLS serves the public health sector, with the majority of patients being from lower socio-economic groups. More than $80 \%$ of the combined population of Nelson Mandela Bay and Sarah Baartman districts are not covered by medical insurance, ${ }^{8}$ and are therefore reliant on the NHLS for pathology services. The sample size was determined by the number of laboratory-confirmed acute hepatitis $A$ cases identified during the three-year study period. Laboratory records were accessed, looking for all positive hepatitis $A$ IgM cases from 2015 to 2017. Laboratory records for liver function tests (ALT) were also accessed. Data on whether or not patients were hospitalised were obtained from hospital and laboratory records, as were age and gender data. 'Hospitalization' referred to hospital admission for one or more days.

All data collected were captured and coded in Microsoft Excel 2010 (Microsoft Corporation, Redmond, WA, USA) and exported for analysis onto Stata 14.1 (Stata Corp 2015. Stata Statistical Software: Release 14; StataCorp LP, College Station, TX, USA). We determined the number of laboratory-confirmed acute hepatitis A cases (defined as patients with clinical features of hepatitis in conjunction with a positive hepatitis A IgM test) and characterised the age and gender demographic as well hospitalisation rates. We additionally analysed the timing of infection to determine whether there was any potential seasonality.

Ethical clearance was obtained from the Human Research Ethics Committee of Walter Sisulu University (protocol number 017/ 2018).

\section{Results}

A total of 194 cases of hepatitis A were identified for the threeyear period from 2015 to 2017 . Of these, 138 (71\%) cases were children 16 years old or younger, with adults accounting for
56 cases (29\%). Figure 1 shows the distribution of cases amongst the various sub-districts of the Nelson Mandela Bay and Sarah Baartman districts.

Amongst children, 77 (55.8\%) were male and 61 (44.2\%) female, whilst the mean age was $14.5 \pm 3.87$ years old. Most cases were from the 6-12-year-old age category (Table 1, Figure 2).

In total, $68 \%$ of children with acute hepatitis A were from the Nelson Mandela Bay district, with 26\% from the Sarah Baartman district, while the remainder were from the Chris Hani district.

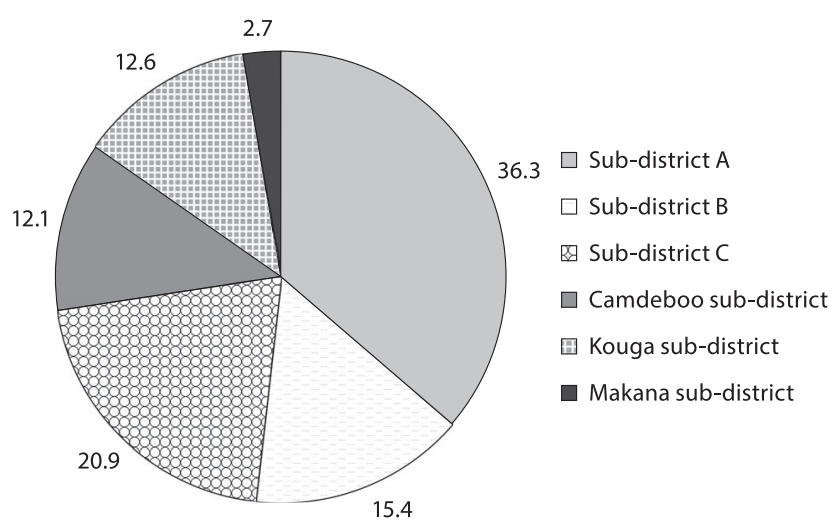

Figure 1: Percentage distribution by sub-district of laboratory-confirmed cases of acute hepatitis A for the Nelson Mandela Bay (subdistrict A, B and $C$ with a combined population size of approximately 1200000 ) and Sarah Baartman districts (subdistricts Camdeboo, Kouga and Makana with a combined population size of approximately 470000 ).

Table 1: Demographic characteristics for children presenting with acute hepatitis A

\begin{tabular}{|c|c|c|c|}
\hline Variable & Category & $\begin{array}{c}n \text { (\%; }[95 \% \\
\text { Cl]) }\end{array}$ & $\begin{array}{c}p \text { - } \\
\text { value }\end{array}$ \\
\hline \multirow[t]{3}{*}{ Age (years) } & $0-5$ & $\begin{array}{l}57(41.3 ;[33.1- \\
49.5])\end{array}$ & 1 \\
\hline & $6-12$ & $\begin{array}{l}67 \text { (48.6; [40.2- } \\
56.9])\end{array}$ & 0.2262 \\
\hline & $13-16$ & $\begin{array}{l}14(10.1 ;[5.1- \\
15.2])\end{array}$ & $\begin{array}{l}< \\
0.0001\end{array}$ \\
\hline \multirow[t]{2}{*}{ Gender } & Male & $\begin{array}{l}77(55.8 ;[47.5- \\
64.1])\end{array}$ & \multirow[t]{2}{*}{0.0541} \\
\hline & Female & $\begin{array}{l}61(44.2 ;[35.9- \\
52.5])\end{array}$ & \\
\hline \multirow[t]{3}{*}{ Hepatitis severity } & Mild $(\mathrm{ALT}<500 \mathrm{U} / \mathrm{L})$ & $\begin{array}{l}27(22.0 ;[14.6- \\
29.3])\end{array}$ & 1 \\
\hline & $\begin{array}{l}\text { Moderate (ALT 501- } \\
1000 \text { ) }\end{array}$ & $\begin{array}{l}32(26.0 ;[18.2- \\
33.8]\end{array}$ & 0.4553 \\
\hline & Severe (ALT > 1000$)$ & $\begin{array}{l}64(52.0 ;[43.2- \\
60.9]\end{array}$ & $\begin{array}{l}< \\
0.0001\end{array}$ \\
\hline \multirow[t]{2}{*}{ Hospitalisation } & Yes & $\begin{array}{l}51(37.0 ;[28.9- \\
45.0])\end{array}$ & \multirow[t]{2}{*}{$\begin{array}{l}< \\
0.0001\end{array}$} \\
\hline & No & $\begin{array}{l}87 \text { (63.0; [55.0- } \\
71.1])\end{array}$ & \\
\hline \multirow[t]{4}{*}{$\begin{array}{l}\text { Time period } \\
\text { (season) }\end{array}$} & Summer (Dec-Feb) & $\begin{array}{l}36(26.1 ;[18.8- \\
33.4])\end{array}$ & 1 \\
\hline & Autumn (Mar-May) & $\begin{array}{l}36(26.1 ;[18.8- \\
33.4])\end{array}$ & 1.000 \\
\hline & Winter (Jun-Aug) & $\begin{array}{l}36(26.1 ;[18.8- \\
33.4])\end{array}$ & 1.000 \\
\hline & Spring (Sep-Nov) & $\begin{array}{l}30(21.7 ;[14.9- \\
28.6]\end{array}$ & 0.3972 \\
\hline
\end{tabular}




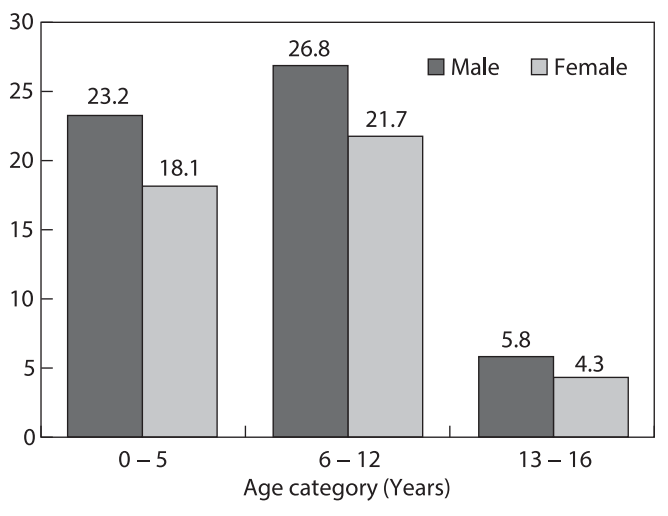

Figure 2: Distribution of children diagnosed with acute hepatitis $A$ by age group and gender.

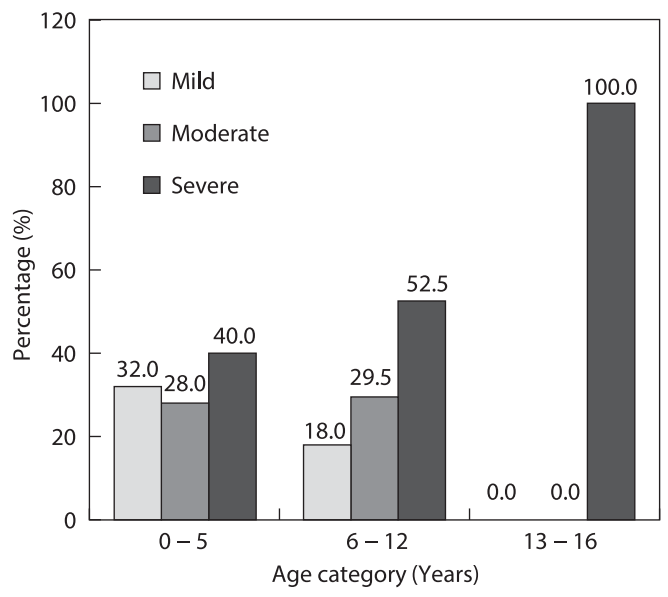

Figure 3: Distribution of children diagnosed with acute hepatitis A by age group and grade of hepatitis.

The severity of hepatitis was graded as mild (ALT < $500 \mathrm{U} / \mathrm{L}$ ), moderate (ALT 501-1 $000 \mathrm{U} / \mathrm{L}$ )) and severe (ALT > $1000 \mathrm{U} / \mathrm{L}$ ). The data regarding hepatitis severity presented in Tables 1 and 2 exclude 23 patients who had no testing for ALT. Older children (13-16 years old) were more likely to have severe hepatitis compared with the $0-5$ and 6-12-year-old categories (Figure 3).

Amongst adults ( $>16$ years of age) diagnosed with acute hepatitis A, 28 (50.0\%) were male and 28 (50.0\%) female. The mean age was $27.2 \pm 10.4$ years old. Most cases were from the 21-30 years category (Table 2, Figure 4).

The majority of adults diagnosed with acute hepatitis A had severe hepatitis on presentation (Figure 5).

\section{Discussion}

This was the first study seeking to describe the hepatitis A epidemic in the Nelson Mandela Bay and Sarah Baartman districts of the Eastern Cape province in South Africa. There is a paucity of data regarding the true incidence of hepatitis $A$ in this region. Based on notifications received from the Outbreak Response Team of the Nelson Mandela Bay Municipality, we sought to determine the magnitude of the problem by identifying the total number of laboratory-confirmed cases over a threeyear period from 2015 to 2017, whilst analysing the demographic characteristics, hospitalisation rates and potential seasonality.
Table 2: Demographic characteristics for adults presenting with acute hepatitis A

\begin{tabular}{|c|c|c|c|}
\hline Variable & Category & $n(\% ;[95 \% \mathrm{CI}])$ & $\begin{array}{c}p- \\
\text { value }\end{array}$ \\
\hline \multirow[t]{3}{*}{ Age (years) } & $17-20$ & $\begin{array}{l}18(32.1 ;[19.9- \\
44.4])\end{array}$ & 1 \\
\hline & $21-30$ & $\begin{array}{l}25 \text { (44.6; [31.6- } \\
57.7]\end{array}$ & 0.1738 \\
\hline & $>30$ & $\begin{array}{l}13(23.2 ;[12.2- \\
34.3]\end{array}$ & 0.2910 \\
\hline \multirow[t]{2}{*}{ Gender } & Male & $\begin{array}{l}28(50.0 ;[36.9- \\
63.1])\end{array}$ & \multirow[t]{2}{*}{1.000} \\
\hline & Female & $\begin{array}{l}28(50.0 ;[36.9- \\
63.1])\end{array}$ & \\
\hline \multirow[t]{3}{*}{ Hepatitis severity } & Mild (ALT < $500 \mathrm{U} / \mathrm{L})$ & $\begin{array}{l}10(20.8 ;[9.3- \\
32.3])\end{array}$ & 1 \\
\hline & $\begin{array}{l}\text { Moderate (ALT 501- } \\
1000)\end{array}$ & $\begin{array}{l}10(20.8 ;[9.3- \\
32.3])\end{array}$ & 1.000 \\
\hline & Severe (ALT > 1000$)$ & $\begin{array}{l}28(58.3 ;[44.4- \\
72.3]\end{array}$ & 0.0002 \\
\hline \multirow[t]{2}{*}{ Hospitalization } & Yes & $\begin{array}{l}18(32.1 ;[19.9- \\
44.4])\end{array}$ & \multirow[t]{2}{*}{0.0002} \\
\hline & No & $\begin{array}{l}38(67.9 ;[55.6- \\
80.1])\end{array}$ & \\
\hline \multirow[t]{4}{*}{$\begin{array}{l}\text { Time period } \\
\text { (season) }\end{array}$} & Summer (Dec-Feb) & $\begin{array}{l}16(28.6 ;[16.7- \\
40,4]\end{array}$ & 0.0353 \\
\hline & Autumn (Mar-May) & $\begin{array}{l}20(35.7 ;[23.2- \\
48.3])\end{array}$ & 0.0041 \\
\hline & Winter (Jun-Aug) & $\begin{array}{l}7(12.5 ;[3.8- \\
21.2]\end{array}$ & 1 \\
\hline & Spring (Sep-Nov) & $\begin{array}{l}13(23.2 ;[12.2- \\
34.3]\end{array}$ & 0.1388 \\
\hline
\end{tabular}

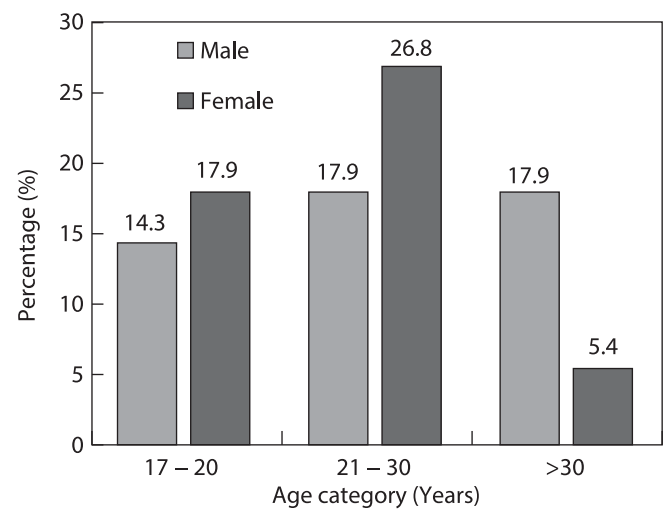

Figure 4: Distribution of adults diagnosed with acute hepatitis A by age group and gender.

There were nearly 200 laboratory-confirmed cases during the study period of three years, highlighting the magnitude of the problem in this region. The majority of cases were from the Nelson Mandela Bay district, which was expected due to the much bigger population size in this region.

A previous study showed that nearly $50 \%$ of children from lower socio-economic groups at 3-5 years of age were seropositive for anti-hepatitis $A$ IgG antibodies, with this number increasing to above $90 \%$ by $17-19$ years of age. ${ }^{7}$ We therefore expected the majority of laboratory-confirmed cases to be children. Indeed, $71 \%$ of cases were children under the age of 16 years, with 


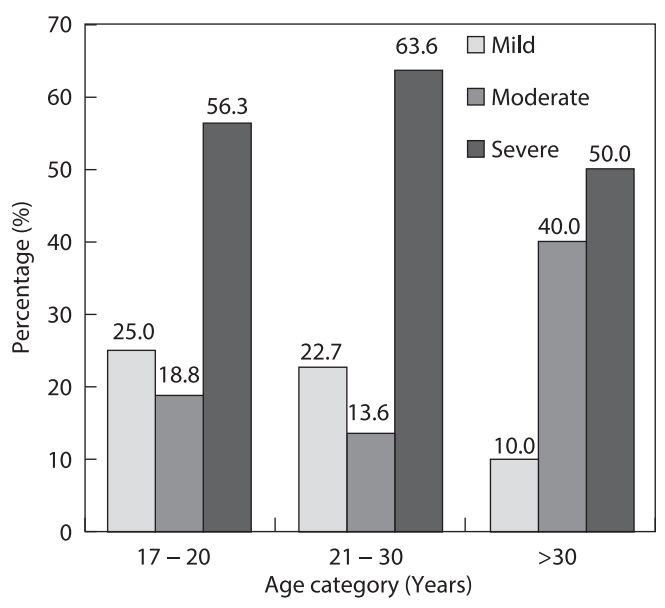

Figure 5: Distribution of adults diagnosed with acute hepatitis A by age group and grade of hepatitis.

$29 \%$ of cases being adults. There was no significant difference between males and females, whilst 37\% of children and $32 \%$ of adults were admitted to hospital for one day or longer. Hepatitis A infection is usually asymptomatic. ${ }^{5}$ However, when patients are symptomatic and seeking medical care, one would expect moderate to severe hepatitis, as evidenced by high levels of transaminases. In both children and adults in this study, the majority of laboratory-confirmed cases presented with severe hepatitis, albeit that for 23 cases in this study no liver function tests were performed.

Similar to other studies, no overall seasonality for acute hepatitis A could be determined. ${ }^{9}$ However, there was a statistically significant difference in adults presenting with acute hepatitis $A$ during summer and autumn months, compared with winter and spring. One possible explanation for this is that adults are more likely to use rivers or dams for recreational purposes or drinking water (which may be faecally contaminated) than very young children, especially during the warmer summer and autumn months. Previous studies from the Eastern Cape have isolated hepatitis $A$ from numerous water sources, ${ }^{10,11}$ albeit that there are no published data for our area specifically. In addition, we know from unpublished data from the Outbreak Response Team of Nelson Mandela Bay metropolitan that most rivers in the area are heavily faecally contaminated, partly due to leakage of untreated sewage into these water sources.

One of the limitations of this study is that it does not provide data on the true incidence of hepatitis $A$, as most patients would be asymptomatic and not seek medical care. In addition, determining the cost to the public health sector of symptomatic cases of acute hepatitis A was beyond the scope of this study but would be important in future studies to highlight the burden of this epidemic, which would hopefully spark a meaningful environmental and public health response.

Whilst South Africa is faced with a myriad of public health issues, most notably related to HIV and TB, less severe diseases such as hepatitis A are often overlooked. However, in districts such as ours, where levels of hygiene and sanitation are low and where we have shown that hepatitis $A$ is indeed a serious problem, we hope that more attention will be paid to this completely preventable disease, with a first step being investigation into the exact cause of this continuing epidemic, such as environmental sampling of rivers and dams in the area, followed by appropriate action to eliminate potential common sources of infection.

Disclosure statement - No potential conflict of interest was reported by the authors.

\section{References}

1. Dr de Jong. GM. NICD Guidelines for the Control of Hepatitis A in South Africa. http://nicd.ac.za/assets/files/NICD\%20Guidelines\% 20for\%20the\%20Control\%20of\%20Hepatitis\%20A\%20in\%20SA.PDF Date accessed 18 May 2015.

2. Costafreda MI, Bosch A, Pintó, M. Development, evaluation, and standardization of a real-time TaqMan reverse transcription-PCR assay for quantification of hepatitis A virus in clinical and shellfish samples. Appl Environ Microbiol. 2006;72(6):3846-3855. doi:10.1128/AEM. 02660-05.

3. Franco E, Meleleo C, Serino L, Sorbara D, Zaratti L. Hepatitis A: epidemiology and prevention in developing countries. World J Hepatol. 2012;4(3):68-73. doi:10.4254/wjh.v4.i3.68.

4. Harrison TJ, Dusheiko GM, Zuckerman AJ. Hepatitis viruses. In Principles and practice of clinical virology, Zuckerman A, Banatvala J, Schoub B, Griffiths P, Mortimer P, editors. Chichester: John Wiley \& Sons Ltd; 2009. p. 273-320.

5. Martin DJ, Blackburn NK, Johnson S, McAnerney JM. The current epidemiology of hepatitis A infection in South Africa: implications for vaccination. Trans R Soc Trop Med Hyg. 1994;88(3):288-291.

6. Koff RS. Hepatitis A. Lancet 1998;351(9116):1643-1649.

7. Schoub BD, Blackburn NK, Martin DJ, McAnerney JM, Sim JGM. Should hepatitis A vaccination routinely given to children? S Afr Med J. 1999;89(10):1074-1075.

8. Massyn N, Padarath A, Peer N, et al., editors. District health barometer 2016/17. Durban: Health Systems Trust; 2017.

9. Chen CM, Chen SC, Yang HY et al. Hospitalization and mortality due to hepatitis A in Taiwan: a 15-year nationwide cohort study. J Viral Hepat. 2016;23(11):940-945. doi:10.1111/jvh.12564. Epub 2016 Jul 7

10. Chigor VN, Okoh Al. Quantitative RT-PCR detection of hepatitis A virus, rotaviruses and enteroviruses in the buffalo river and source water dams in the eastern cape province of South Africa. Int $J$ Environ Res Public Health. 2012;9(11):4017-4032.

11. Sibanda T, Okoh Al. Real-time PCR quantitative assessment of hepatitis $A$ virus, rotaviruses and enteroviruses in the tyume river located in the eastern cape province, South Africa. Water SA. 2013;39(2):295304. 